\title{
Efficacy of farmer field schools in achieving participatory technology development among smallholder farmers in the Hoima district, Uganda
}

\section{David Mwesigwa}

Discipline of Public Administration and Management, Lira University, Lira, Uganda

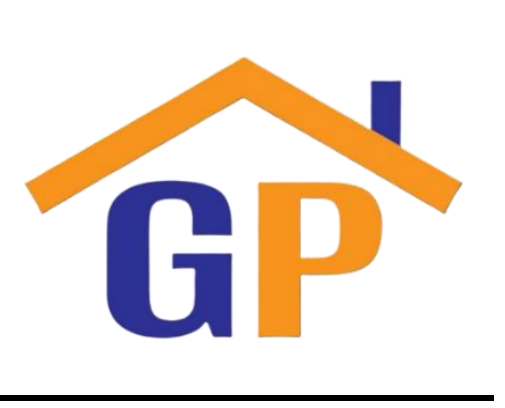

Article History

Received on 26 July 2021

Revised on 24 August 2021

$2^{\text {nd }}$ Revision on 25 August 2021

Accepted on 26 August 2021

\section{Introduction}

\begin{abstract}
Purpose: This study investigated the efficacy of FFS for participatory technology development among smallholder farmers in Hoima district, Uganda. It is anticipated that by making FFS concrete, household food security will be enhanced.
\end{abstract}

Research methodology: The study utilised primary data, which was collected using a self-administered questionnaire. While 120 respondents were sampled, 103 responded, generating a response rate of $85.83 \%$. This was an excellent response seeing that it merited above $75 \%$. The researcher administered all questionnaires in one month.

Results: From the findings indicate that PTD is more desirable in the Hoima district. In addition, the construct of the ability to solve problems from time to time indicates that problem-solving is very desirable for PTD in the Hoima district. The results suggest a positive correlation between FFS and PTD among the study population, indicating that a unit-change in the FFS constructs will lead to a proportionate change in the constructs of PTD in the same direction. This implies that improving FFS quality by a single unit will translate into progressive improvement in PTD in the Hoima district. This study also suggests that FFS alone has a strong positive influence on PTD in the Hoima district.

Limitations: This study merely covered farmer-field schools, yet several interventions aim to raise the quality of agriculture in Uganda, such as National Agricultural Advisory Services and Emyoga.

Contribution: This study contributes to the deeper understanding of what ought to be done to improve the quality of farming in Uganda.

Keywords: Farmer field school, Participatory technology development, Smallholder, Agricultural extension, Agriculture

How to cite: Mwesigwa, D. (2021). Efficacy of farmer field schools in achieving participatory technology development among smallholder farmers in the Hoima district, Uganda. Journal of Social, Humanity, and Education, 1(4), 309-321.

The approach dubbed Farmer field school (FFS) came as an advanced, hands-on and collaborative learning platform that emphasises solving a particular problem and learning based on innovation. This approach diverts away from traditional approaches, which assume that learners know nothing and should be informed about how to do them and why they should do such. While FFS is also known by other names, such as farmer-to-farmer extension, FFS believes that the target group has a lot of 
knowledge and skills that they can share amongst themselves both as an enriching and innovative platform (Kiptot \& Franzel, 2019). A study by McDonald, Corfield, Macleod and Lisson (2019) reveals that the core of FFS is to enhance the potential of farmers to study their systems and or structures of production, ascertain the challenges which participants encounter, assess the potential choices, and then inspire the members to embrace the practices that are most appropriate to their farming systems and or structures. This view suggests that the farmer's choices emerge from within them as a group rather than being superimposed by the central government or local government authorities as an opportunity for the farmer-controlled, peer-to-peer exchange of information (O'Connor, Meredith, McNamara, O'Hora \& Kinsella, 2020). By so doing, the farmer becomes an outright decision-maker of their business right from the beginning of the production cycle. This is what Gillespie and Smith (2008:329) call building relationships that support health and wellbeing.

The FFS approach is not an innovation seeing that it is already being implemented in a number of countries within and outside Africa. The global farmer field school offers a system for stakeholders working on field schools by exchanging the progress and espousal of viable packages to facilitate the transformation of farming and food systems to become more sustainable, resilient, and inclusive (The FFS global platform facilitating team, n.d). In the Middle East, Latin America, and Africa, FFS is a system of training that applies experimental learning techniques to shape the expertise of farmers (Van Den Berg and Knols, 2006). In Kenya, approximately 600,000 smallholder farmers are benefiting from FFS through the Kenya tea development agency as an intermediary. The agency gives an opportunity to individual members to gain abilities and awareness on profitable farming practices by raising both the value and volume of produce (Ethical tea partnership, 2021). In Ghana, the spring organised a prospectus with a vision of improving agricultural practices and growing aflatoxin-safe groundnut crops for healthier family nourishment (USAID, n.d). In Uganda, FFS offer an experiment and reflection of vital components of the agroecology by assessing plant growth, sampling the pests, wild plant and unhealthy plants, as well as building modest cage testing or relating features of diverse soils (Food and agricultural organisation of the United Nations, 2016).

On a global scale, the neoliberal economic policies run contrary to measures essential for substantial and sustained farming in terms of philosophy, institutions and benefits (Madariaga, 2020). A number of policy pathways underlined in the Washington consensus have contributed to dampening reduction in agricultural production in the East African region (EAC). For example, fiscal discipline is an essential feature of neoliberal economic policies. This implies reducing the fiscal deficit in the government budget as far as possible and hence cuts in public investments. Consequently, governments are unable to invest adequately in open agricultural subsidies such as using the pathways of FFS. Similarly, fiscal liberalisation makes nations vulnerable to crises resulting from speculative dealings in agriculture. The sub-Saharan African food crisis has been a direct consequence of financial speculation and caused a major setback in terms of poverty reduction in the region. In their study, Chiaro and Rossat (2015:237) reveal that food is essential for human wellbeing and health and is rooted in the traditional character of individuals. Financial liberalisation has in many nations resulted in a shrinking of economic services available to smallholder farmers and FFS. Smallholder farmers have had to put up with the middle-men and women who exploit them with meager agricultural prices at the farm-site and only to sell those products at an exorbitant price in the national or international food market. That is probably why a study by Eton, Mwosi, Ejang and Poro (2020:2) revealed the need to integrate smallholder farmers into commercial agriculture. This notion is further justified by the fact that a number of smallholder farmers fail to guarantee availability of food at the household between seasons (Vercillo, Kuuire, Armah \& Luginaah, 2015:1).

The argument is that financial crunches tend to distress the incomes of those employed in the agricultural sector-moreover, several more whose source of revenue hinges on the sector and its labours lost jobs. Neoliberal policies have a great consequence on food security (once every individual continuously have access to an adequate, non-toxic and nourishing diet to sustain a strong dynamic life (Tian, Bryksa \& Yada, 2016, 155; Hwalla, El Labban \& Bahn, 2016:167)) through bumpy prices of gardening, dawdling progress in agricultural production, speculation in the farming supplies and the variation of agricultural produce as well as productive land to the making of biofuels. 
A problem currently affecting much of humanity in contemporary societies (Besada \& Werner, 2015:120). These have perpetuated pauperisation of the smallholder farming by raising the food prices when, in fact, reduction in public investment in agriculture and cuts in government subsidies for agri-inputs has resulted in high cost of production with less net profit.

Therefore, it is important to note that the FFS approach unlocks an opening for smallholder farmers to take up and appraise obtainable but viable technologies for utilising available land and acquaint themselves with fresh know-hows through comparison of their orthodox technologies with their individual customs and values. In particular, increased extension services increased convenience to credit and guaranteed appropriate obtainability of technologies at a reasonable amount (Shita, Kumar $\&$ Singh, 2020). This way, FFS are perceived to be a great advantage that can facilitate farmers to think outside the box rather than being forced by government authorities. In a number of cases, when farmers are forced to either abandon or adopt new technology, in the belief that the traditional technology is obsolete and that the new technology is more useful, the government authorities oftentimes face numerous resistance from the target group (Séogo \& Zahonogo, 2019; Rocha, Goncalves \& Almeida, 2019; Feyisa, 2020). Logically, such resistance is valid, seeing that government authorities often believe that their intentions are constructive by thinking for and on behalf of the local population. Yet, when the affected group is given an opportunity to think and assess their own situation, they can develop a more sustainable strategy to solve current and future challenges. This is the philosophy of FFS from the perspective of smallholder farmers.

It is eminent that FFS is a time guaranteed action comprising a cluster of approximately 25 farmers, which is aided by either an agricultural extension staff (AES) or by farmer facilitators (FFs). Hence, the bottom line here is facilitation for rather than the provision of, suggesting that FFS is an avenue for farmers to enhance their own abilities, skills, and values to become better in what they do and how they do them. This process puts emphasis on the group by allowing and facilitating it to observe, deliberate, examine, present and get to a joint conclusion for action (McDonald et al., 2019). In this situation, the main element of FFS is the invention of a virtual experiment called participatory comparative experiment (PCE), ordinarily identified as PTD. This try-out facilitates smallholder farmers to position the FFS idea into action, given that the PCE can be established via a wide range of agri-enterprises ranging from crop growing to raring of livestock.

During the process of learning in an FFS, the demonstration of outcomes from the PCE by members from different groups is a central action. It lets participants critique each other's works before arriving at a conclusion. By itself, the FFS platform inspires participants to speak on their outcomes, involvements, and awareness in the presence of other FFS fellows while justifying their view on conclusions and choices made (O'Connor et al., 2020). Through this method, participants become more self-confident, mainly for females, members from poor households, or marginal individuals such as persons with disabilities and persons born with albinism. An additional result is that since every FFS has an obligation of having an elected set of frontrunners, namely, chair, assistant chair, general secretary and financial officer, the frontrunners develop group leadership abilities. Also, the FFS group is dissected into about five smaller groups and each smaller group is expected to have a leader. Consequently, by handling the FFS assembly and or smaller group, these elected frontrunners and the other participants are offered an opportunity to accumulate abilities for leading a group. In addition, FFS boost interrelatedness amongst members and advances team spirit. Studies reveal that a number of FFS groups carry on even afterwards the FFS learning phase is concluded so as to benefit from shared issues such as joint disease control and pest management as well as sale of crop produce and animal products (Lewison, 2019; Ouma, Onyango, Ombati \& Mango, 2020; Skogstad, 2020). However, in order to realise the projected benefits from the FFS, the members should adhere to a number of principles as presented later in this paper.

The article takes a close examination of the present-day accounts on FFS projections as an instrument for attaining PTD in Uganda. It endeavours to deliberate on the FFS concerns and inferences for PTD objectives to secure adequate food security at the household. Especially, the article scrutinises the correlation between FFS and PTD, underlining the effect of the former to the least. In the article, the 
researcher interrogates the correlations between the two variables characteristically treated as dogma by both practitioners and advocates of FFS. It should be stressed that this article is not intended to bring forth a basis for or against position on FFS but to place the discussion about FFS modus operand in the concerns of PTD that affect the livelihoods of a number of smallholder farmers in Uganda.

Section one provides an extensive overview of FFS and debates their impact at the different levels and in a number of countries. A review of the core principles of FFS and the politics involved therein follows; here, it is central to reflect on the consequences of FFS preference where agriculture is commonly lop-sided in the direction of either the rich commercial producers or the rural poor who are struggling to put food on their dining table. Section two comprises the study problem preceding methodological issues. Section three presents the findings along with the four study objectives, followed by section four, the discussion of findings. The article concludes that FFS limits serve as severe hurdles to realising successful PTD and, broadly, the remaining task of relating PTD to intricate existent FFS snags have confidence in the substantial academic evolution that academics on FFS have completed over the previous few years. PTD has been linked with the emblematic FFS that overlooks the field. Maybe the most significant leaning in modern-day FFS, though, is the advent of methods that merge both FFS and PTD; hence the significance of evolving more meaningful FFS structures by openly involving the smallholder farmers and their groups as participants is so situation explicit. The inferences of the systems dynamics model (SDM) highlighting the FFS could facilitate intermediaries to follow their private objectives of pushing FFS for higher output that increase the supply for exporters and further relegate the susceptible smallholder farmer in Hoima.

\section{Statement of the problem}

Given that agriculture is the backbone of Uganda's economy, employing more than $80 \%$ of the labour force, the sector has not been growing at pace with sectors within the same economy. Compared to other sectors, agriculture is projected to grow even faster so as they give hope to the many people engaged in the sector. One way to grow the sector is through improved agricultural extension services and other direct sectoral reforms such as operation wealth creation, national agricultural advisory services, prosperity for all and plan for modernisation of agriculture, to mention but just a few. These reforms ought to be punctuated by robust farmer-based organisations where they can acquire indigenous knowledge and skills that are home-grown rather than relying on the foreign-based technologies whose application and appreciation have remained problematic to many a farmer. One of those pathways to achieving a user-friendly acquisition of knowledge and skills is FFS. However, very few studies have been conducted on the subject in spite of its significance. Therefore, this study aimed to examine the efficacy of FFS in achieving participatory technology development among smallholder farmers in the Hoima district.

\section{Literature review}

\section{The core principles of FFS}

From available studies, a set of eleven principles of FFS is identified, namely:

The field is the workroom - every learning is conducted in a real-life atmosphere, typically on a selected farm that has an established PCE and every learning is conducted there (Hunter, Williamson, Pearson, Saikawa, Gribble \& Kegler, 2020). Members are expected to observe and study from the field rather than from manuals and talks from agricultural extension staff. It is important to note, here, that enhanced agri-practices are essential for the farmers in that area, seeing that these are inclined to local environmental and socioeconomic circumstances and the varied preferences of farmers. This view negates the traditional practice of a number of leaders who believe that learning requires taking farmers to a distant place or even outside the country where environmental conditions are completely different.

Two, importance is placed on facilitation instead of coaching - the core of responsibility of an enabler is fundamental for effective learning and enablement since FFS does not emphasise coaching but on managing FFS participants by way of learning. To nurture the learner-focussed method, the enabler meres listens and mirrors, probes questions, and inspires members to explore more and present their 
thoughts (Rusere, Crespo, Dicks, Mkuhlani, Francis \& Zhou, 2020). The enabler should encourage FFS participants to examine and ascertain solutions on their own. Practical and discovery-based - the learning method is prepared in line with the values of mature education in which grownups don't study nor adjust performance through inactive attending but from practice. Through hands-on learning, participants become owners over their information and increase self-reliance in what they have been exposed.

Three, the farmer as an experienced individual - the approach of FFS appreciates members of a community as experienced in their specific spaces and considers the significance of native knowledge for FFS achievement (Etana, Holm, Rydberg \& Keller, 2020). Consequently, participants study how to boost their capacity to detect and evaluate problems and seek hands-on and appropriate ways out. This encourages members to learn by themselves about concerns and issues affecting their incomes.

Four, fairness and absence of bureaucracy - an FFS is intended for everyone to take part on an identical basis (Zhang, Wu, Simpson \& Arthur, 2019). FFS upholds no bureaucracy between agriculturalists and facilitators, leaders of clusters and average memberships, and the illiterate. All are identical associates in the FFS process of learning.

Five, fused and learner-centred syllabus - the FFS programme of study is defined by the participants and is exclusive for individual groups, although considerable learning initiatives are pre-planned by the directive of FFS executing partners. The essential norm of any FFS is that every issue needs to be associated with what is essential to the group and target to accomplish a specific knowledge requirement.

Six, relative testing - information is acquired using hands-on tests where a variety of possibilities are relative to each other. The tests are frequently observed and examined with any emerging issues being deliberated upon as they arise in terms of time, for example, the period for an egg to hatch on a poultry farm.

Seven, agroecological examination - the agroecological examination (AEA) is one of the foundations of the FFS approach, which every FFS member accomplishes at every stage of the FFS sequence (Orina, Mukundi, Adimo, Rimberia, Omondi, Gebauer \& Kehlenbeck, 2021). It embraces three issues, viz., observation, analysis and exhibition for blending and debate. This phase enriches the abilities of participants to scrutinise their outcomes. This improves their understanding as well as communication skills.

Eight, exceptional issues - the emphasis of exceptional issues are determined by the members and contributes much to the FFS. Exceptional issues can centre on extensive problems covering several sectors. The choice of issues ought to be driven by demand and should address broader aspects of livelihood. These exceptional issues can likewise be facilitated by outside personnel instead of the FFS traditional facilitator.

Nine, team structure and collective enthusiasm - aspects of team structure, changes within a group and collective enthusiasm are essential elements of FFS. Through melodies, dance and comedy, members share information and values, become united and connect better (Masset \& Haddad, 2015). This generates an opportunity for addressing problematic topics such as manipulation and domestic violence.

Ten, participatory monitoring and evaluation - members develop a strategy for checking and appraising success to gauge whether they realise the set goals when preparing the FFS syllabus.

\section{A glance at PTD}

The notion PTD is clear when seen from the perspective of smallholder farmers suggests that economic growth hinges on the involvement of grassroots communities in technologies that are deemed beneficial to them. Indeed, relations between scarcity, economic inducements, institutional 
flaws in government, and smallholder farmers have become more evident than ever before in the East African region. Notwithstanding the government's determination to focus much attention on the smallholder farming communities in terms of hands-on interventions such as National agricultural advisory services (NAADS), prosperity for all (PFA), Operation wealth creation (OWC), Youth livelihood program (YLP), women entrepreneurship program (WEP) and now the Emyooga program, smallholder farmers' level of comfort continues to shrink. Consequently, the involvement of smallholder farmers at numerous phases during expansion of obtainable skills turns out to be essential. This enables the merger of old-style skills with scientists' understanding to grow applicable expertise for a viable development of agriculture; guarantees the involvement and empowerment of smallholder farmers in the expansion process; and, bring about economic progress through transformative smallholder farming.

In this study, the system dynamics model (SDM) was adapted owing to its appropriateness in providing an assimilated examination of policy preferences associated to diverse issues in multifaceted systems of economics, communal, ecological, and decision-making (Zheng \& Huang, 2018). As a consequence of twists in the aspects of interconnection and feedback in its investigative structure, the SDM was appropriate in providing greater understandings than one imaginable with related frameworks, for example, optimisation and econometrics. The SDM approach has been described as a useful framework in a number of studies and policy analyses that are intended for superior decision-making, socio-economics and agricultural studies when leading studies in public policy. In their study, Vaghefi, Shamsudin, Radam and Rahim (2016:20) note that SDM can be useful for policymakers as an experimental workshop. While this model is well-matched to study policy dynamics, such as that of FFS, there is no obtainable study in Uganda that has adopted the model in the area of farming. Thus, an SDM is developed by the researcher, suggesting a causal loop interrelationship among components of the model with the application of each FFS constructs. As a consequence, a change in one construct in FFS is projected to cause an effect (positive or negative) in the degree of PTD.

\section{The contextual perspective of FFS in Uganda}

Much of the population in Uganda live in rural areas and more than $80 \%$ depend on farming to ensure that their livelihoods are maintained (Templer, Hauser, Owamani, Kamusingize, Ogwali, Mulumba, Onwonga, Adgna \& Probst, 2018). Obtainable studies suggest a massive decline in agricultural productivity at the micro-level thus translating into declining livelihood for many rural people. Overall food output in Uganda has been dropping steadily and it is not about to recover in the near future. There are a number of factors contributing to this trend, including land ownership, land degradation, increased reliance on fertilisers and a dearth of interest to practices that aim to conserve available land. These and many other factors have and continue to contribute to wide-scale land degradation, which is not addressed is likely to perpetuate a state of hopelessness among much of the population. While the government is seen to be the biggest provider of agricultural extension services, its providence remains inadequate and poor for most of the population in the country.

One of the strategies that have been hoped after as a way of complementing the efforts of the government in enhancing the livelihoods of farmers is the ecological livelihoods agenda. This agenda is appropriate in analysing smallholder farming populations, particularly the rural-based, who may perhaps be forced to work by need and their agricultural preferences can be inhibited by setting, expertise and level of awareness. However, whatever they do is fundamentally up to them (Thompson, 2015: 343). The agenda is a result of discussions on rural progress. A livelihood is described in terms of specific resources such as human, natural, social and physical, the actions and means to accessing the aforesaid at both single and collective levels. A livelihood becomes ecological when it can deal with and recuperate from pressures, preserve its proficiencies and resources while not destabilising the natural resources. Therefore, it is essential to bring the debate on livelihoods into the perspective of FFS, seeing that these FFS are not just luxury associations; they are, in fact, strategies aimed to increase per capita productivity of a household as a way of enhancing household and community livelihoods in the medium-term. So issues of access, distribution and consumption 
become handy in this debate and seek attention by focussing on the efficacy of FFS in achieving their goal of learning based on innovation among farmers in mid-western Uganda.

Adoption of FFS can be beneficial to farmers in a number of ways, namely: First, embracing FFS is likely to reinforce observation ability and enhance information proprietorship using innovative learning. This is so seeing that farmers are stimulated to have informed decision making to facilitate original information and drills by farmers. Second, embracing FFS builds assurance and enriches managerial capacity - this benefits farmers in several elements by building self-reliance and making choices as members are assisted to lead roles. Third, FFS lessen possibilities of suffering from novel practices as they offer farmers an opening to test original practices on a set where threats are negligible and possible damages can be suffered by every member. Fourth, FFS can change entrenched dogmas and practices by offering systematic and consistent interfaces with the field, trainers, and group associates. And fifth, FFS can develop problem-solving abilities by proposing unified learning prospects in which participants obtain problem-solving abilities for confident conduct and attitude.

The FFS can even be necessary, seeing that the widely professed modern farming technologies have not been extensively espoused in Uganda. They have had a very narrow role in agricultural efficiency and returns of smallholder agriculturalists to alleviate concerns of food uncertainty (Adong, 2014). These technologies are many as they embrace machinery, modern varieties of planting materials, use of enrichers and insecticides, modern organisational practices, as well as the use of computers (Vercillo et al., 2015). Nevertheless, the feeble institutional structure coupled with meagre advertising structure and inadequate access to resources, the espousal of expertise dubbed green revolution remains narrow. For example, the adoption of fertilisers and espousal of irrigation remains very low compared to the global statistics, thus suggesting a meagre adoption rate for much of Africa and Uganda in particular. With this at the back, embracing FFS is seen as a timely saviour to improved agricultural production and productivity and enhanced household food security.

\section{Research methodology}

Much of the data for this research were collected from both primary and secondary sources of FFS in various parts of Uganda, Africa and beyond. Primary data involved information about particular FFS at the sub-county level gathered during site visits to six sub-counties in the Hoima district. The data were gathered using a researcher-designed self-administered questionnaire (SAQ) with FFS members and their facilitators, observations, and document analysis. Consequently, a total of 103 out of the sample of 120 respondents responded, thus generating a response rate of 85.8\%. Secondary information about FFS in Uganda was gathered from obtainable books, journals, newspapers, websites and local government periodical reports. The primary data were analysed using both descriptive statistics and inferential statistics, respectively. Hoima district is one of the eight districts that currently form mid-western Uganda, commonly known as the Bunyoro region. The other districts are Masindi, Buliisa, Kiryandongo, Kikuube, Kagadi, Kibaale and Kakumiro as well as the newly created Hoima city (Mawa, Babweteera \& Tumusiime, 2020). The district is made of Kigorobya town council, Kigorobya sub-county, Kabaale sub-county, Buseruka sub-county, Kitoba sub-county, Kyabigambire sub-county, Kyabigambire town council and Buhanika. The biggest percentage of households in the district are farmers engaged in both crop husbandry and animal husbandry practiced on both small-scale and medium-scale. The study was concentrated in the three sub-counties of Kitoba, Kyabigambire and Kabaale. A survey conducted by the researcher revealed that there were not many FFS openings in the district. By the end of 2019/20 financial year, the district had approximately 24 active FFS, and by the end of the 2020/21 financial year, the number had dropped to a paltry 12 as a result of nationwide lock-downs resulting from the Covid-19 pandemic. These were scattered across the entire district.

\section{Purpose and objectives}

This study investigated the efficacy of FFS for participatory technology development among smallholder farmers in Hoima district, Uganda. Specifically, the study was based on four objectives, namely to (a) examine the level of FFS among smallholder farmers in Hoima district; (b) examine the 
degree of PTD among smallholder farmers in Hoima district; (c) examine the effect of FFS on PTD among smallholder farmers in Hoima district; (d) examine the relationship between FFS and PTD among smallholder farmers in Hoima district. To achieve the purpose of tis study, results are presented on a set on five tables: Table 1 highlights the 1evel of FFS and PTD among smallholder farmers in Hoima district; Table 2 illustrates the Bivariate correlation between FFS on PTD among smallholder farmers in Hoima district; Table 3 presents the effect of FFS on PTD among smallholder farmers in Hoima district; Table 4 illustrates the Coefficients; Table 5 gives the scores and ranking of factors limiting the success of FFS among smallholder farmers in Hoima district.

\section{Results and discussions}

This section is organised along themes emerging from each of the four objectives of the study, viz.; the level of FFS among smallholder farmers, the degree of PTD among smallholder farmers, the effect of FFS on PTD among smallholder farmers, and the relationship between FFS and PTD among smallholder farmers.

\section{The level of FFS among smallholder farmers in the Hoima district}

In order to examine the level of FFS, analytical statistics were applied using means $(\mu)$ and standard deviations (Std. Dev.) for each of the constructs and indicated in table 1 below.

Table 1. Level of FFS and PTD among smallholder farmers in Hoima district ( $n=103)$

\begin{tabular}{|c|c|c|c|c|}
\hline FFS constructs & Min. & Max. & $\mu$ & Std. De \\
\hline Analysis of the system of agricultural production & 1 & 5 & 3.41 & 1.052 \\
\hline Ability to identify existing problems & 1 & 5 & 3.48 & 1.028 \\
\hline Ability to test possible solutions to existing problems & 1 & 5 & 3.72 & 1.030 \\
\hline $\begin{array}{l}\text { Ability to adopt the practices most suitable to the } \\
\text { systems of farming }\end{array}$ & 1 & 5 & 3.67 & 0.983 \\
\hline $\begin{array}{l}\text { Ability to practice and evaluate sustainable land-use } \\
\text { technologies }\end{array}$ & 1 & 5 & 3.35 & 1.018 \\
\hline $\begin{array}{l}\text { Ability to introduce new technologies through } \\
\text { comparing their conventional technologies with their } \\
\text { own tradition and culture }\end{array}$ & 1 & 5 & 3.41 & 1.052 \\
\hline $\begin{array}{l}\text { Average level of FFS } \\
\text { PTD constructs }\end{array}$ & $\mathbf{1}$ & 5 & 3.48 & 1.028 \\
\hline $\begin{array}{l}\text { Ability of observation and knowledge ownership } \\
\text { through discovery learning }\end{array}$ & 1 & 5 & 3.95 & 1.026 \\
\hline Self-confidence and decision-making & 1 & 5 & 4.03 & 0.896 \\
\hline $\begin{array}{l}\text { Ability to minimise risks in experiencing with new } \\
\text { practices }\end{array}$ & 1 & 5 & 3.41 & 1.117 \\
\hline Ability to change deep-rooted beliefs and practices & 1 & 5 & 3.68 & 0.984 \\
\hline Ability to solve problems from time-to-time & 1 & 5 & 4.27 & 0.885 \\
\hline Average level of PTD & 1 & 5 & 3.87 & 0.981 \\
\hline
\end{tabular}

Legend: less-than 1.00 (not desirable), $1.00-1.99$ (less desirable), $2.00-2.99$ (desirable), $3.00-$ 3.99 (more desirable), 4.00 - 4.99 (very desirable)

Source: Primary data

The findings in table 1 above illustrate that FFS with an average of 3.48 is more desirable to the farmers in the district of Hoima. The study also established that the respondents agreed with all the six constructs presented to them that FFS were more desirable in the district.

\section{The degree of PTD among smallholder farmers}

The findings in table 1 above indicate that PTD with an average mean $(\mu)$ of 3.87 and an average standard deviation (std. dev.) of 0.981 is more desirable in the Hoima district. In addition, the construct of ability to solve problems from time to time had the highest score $(\mu=4.27 \&$ Std. Dev. $=$ 0.885), indicating that problem solving is very desirable for PTD in the Hoima district. 


\section{Correlation between FFS and PTD}

The researcher conducted a bivariate correlation test to determine the strengths and the degree of relationship between FFS and PTD. The correlation results suggest a positive relationship between the two variables $(r=.745 ;$ Sig. $<.01)$.

Table 2. Bivariate correlation between FFS on PTD among smallholder farmers in Hoima district

\begin{tabular}{llllll}
\hline Variable & & $\mathbf{1}$ & $\mathbf{2}$ & $\mathbf{3}$ & $\mathbf{4}$ \\
FFS & Pearson correlation Sig. (2-tailed) & $.714^{* *}$ & $.761^{* *}$ & 1 & \\
& & .000 & 0.000 & .000 & \\
PTD & Pearson correlation Sig. (2-tailed) & $.745^{* *}$ & $.742^{* *}$ & $.668^{* *}$ & 1 \\
& & .000 & .000 & .000 & .000 \\
\hline
\end{tabular}

**correlation is significant at the 0.01 level (2-tailed)

Source: Primary data.

The results in the table above suggest a positive correlation between FFS and PTD among the study population, indicating that a unit-change in the FFS constructs will lead to a proportionate change in the constructs of PTD in the same direction. This implies that improving FFS quality by a single unit will translate into progressive improvement in PTD in the Hoima district.

\section{The effect of FFS on PTD}

A regression test was carried out to establish the effect of FFS on PTD, a regression test was carried out and the results obtained are presented in table 3 below.

Table 3. Effect of FFS on PTD among smallholder farmers in Hoima district

\begin{tabular}{lllllll}
\hline Model & & r & r-square & $\begin{array}{l}\text { Adjusted } \\
\text { square }\end{array}$ & $\begin{array}{l}\text { Std. error of } \\
\text { estimate }\end{array}$ \\
1 & Predictors: (Constant) PTD & .745 & .554 & .599 & .461 & \\
\hline
\end{tabular}

Source: Primary data.

The model summary of regression produced an adjusted $\mathrm{R}^{2}$ of 0.599 , which means that FFS contributed up to approximately $60 \%$ of PTD in the Hoima district. The remaining $40 \%$ was contributed by other factors outside this study, which were not covered in the scope. Secondly, a t-test was conducted to establish the effect of FFS on PTD in the Hoima district. The results obtained are presented in the table below.

Table 4. Coefficients ${ }^{\text {a }}$

\begin{tabular}{|c|c|c|c|c|c|}
\hline Model & $\begin{array}{l}\text { Unstandardised } \\
\text { coefficients } \\
\text { B }\end{array}$ & Std. error & $\begin{array}{l}\text { Standardised } \\
\text { coefficients } \\
\text { Beta }\end{array}$ & $\mathbf{t}$ & Sig. \\
\hline (constant) & .681 & .302 & & 2.250 & .027 \\
\hline PTD & 733 & .077 & .745 & 9.429 & .000 \\
\hline
\end{tabular}

a. Dependent variable: PTD

Source: Primary data.

The results of the coefficients yielded a Beta of .745 with a p-value less than 0.05 . This suggests that FFS alone had a strong positive influence on PTD in the Hoima district.

Table 5. Scores and ranking of factors limiting the success of FFS among smallholder farmers in the Hoima district

\begin{tabular}{ll}
\hline Factor & Rank \\
Level of experience among FFS group facilitators & 3 \\
The mechanism for appropriate release of funds and effectiveness of & 2 \\
$\begin{array}{l}\text { logistics } \\
\text { Availability of mechanisms for quality control }\end{array}$ & 3 \\
\hline
\end{tabular}


The level of price volatility 1

Availability of tools for monitoring the progress of FFS 2

Average $\quad \mathbf{2 . 2}$

Legend: $3=$ very significant, $2=$ significant and $1=$ less significant

Source: Primary data.

The rankings of views from respondents regarding the factors limiting the success of FFS in the Hoima district are itemised in Table 5 above. For the five factors presented to respondents, the average response is 2.2 , which is very close to 2 (significant) on the legend. This suggests that all of the five factors have a significant impact on the success of FFS in the district and should not be taken for granted by the local government management.

\section{Discussion}

The study reveals that FFS is more desirable to the farmers in the district of Hoima and so is PTD. This view in agreement with a study conducted by Adong (2014), who established a reasonable indication of the progressive effect of households' involvement in farmers' groups on the espousal of methods, for example, making usage of better-quality seeds, biological compost as well as enhanced livestock varieties. However, this outcome is in the opposite direction with a study conducted by Ibnu, Offermans and Glasbergen (2018) in Bangladesh, revealing that the specialised farmers had greater benefits than unspecialised farmers; also, prepared farmers had greater paybacks than their counterparts who are not organised. In addition, the results suggested a positive correlation between FFS and PTD among the study population, indicating that a unit-change in the FFS constructs will lead to a proportionate change in the constructs of PTD in the same direction. This implies that improving FFS quality by a single unit will translate into progressive improvement in PTD in the Hoima district. A similar study conducted by Gardeazabal, Lunt, Jahn, Verhulst, Hellin and Govaerts (2021) established a dearth of precision in the general objectives for the efficacy of PTD, basic disengages, and dynamics that deter affirmative variations at diverse measures. Nonetheless, another study conducted in central Africa by Ochieng, Knerr, Owuor and Ouma (2018) found that farmer groups with solid internal structures and greater participation in product bulking and formally organised groups with stable external factors links significantly have higher marketing performance.

While the results do not show the relevance of SDM, it is noticeable that FFS alone had a strong positive influence on PTD in the Hoima district, thus supporting the findings of Otte, Tivana, Phinney, Bernardo and Davidson (2018) on gender and agricultural technology development which noted the unrivalled distribution of overheads and profits between the different genders since women had a smaller amount time and a number of phases in the procedure are gender alienated. The mean response of 2.2 regarding the factors limiting the success of FFS is very critical for local managers, as earlier revealed by Murisa (2011), whose study conducted in Zimbabwe established challenges of inaccessibility of resources, inadequate workforce and inaccessibility of inputs. Also, a study by Makokha, Yongo, Mwirigi and Nyongesa (2019) conducted in Kenya established that vulnerabilities reduced performance and the high proportion of inactive members reduced performance as well, suggesting the dearth of the relationship between group performance and initial conditions. In essence, FFS have a great potential of transforming the agricultural sector, especially once the smallholder farmers become successful, albeit at a micro-level. According to Nevarez, Tobin and Waltermaurer (2016:20), the surging number of commercial farmers in the country, smallholder farmers will benefit seeing that the level of complementary will be high enough for them to avoid falling back into household food insecurity (commonly referred to as limited availability of nutritionally adequate and safe foods or limited ability to acquire acceptable foods in socially acceptable ways.

\section{Conclusion}

The results of this study have revealed the need for stakeholders to pay close attention to FFS. This is so because, at the moment, the limits to FFS serve as severe hurdles to realising successful PTD. Nonetheless, the remaining task of relating PTD to intricate existent FFS snags have confidence in the 
substantial academic evolution that academics on FFS have completed over the previous few years. Can PTD make a similar kind of remarkable running away as other agricultural interventions? PTD has been linked with the emblematic FFS that overlooks the field. Maybe the most significant leaning in modern-day FFS, though, is the advent of methods that merge both FFS and PTD. Presently, these methods are too relaxed. Nonetheless, if they recognise their potential, they may transcend the impediments that have restricted actual uses of PTD thus far. Consequently, by using farmer field schools, Hoima district is likely to enhance participatory technology development. These views attest to the views raised under the SDM approach for superior decision-making, socio-economics and agricultural studies when leading studies in public policy. The results show that SDM can be useful for policymakers as an experimental workshop. While this model is well-matched to study policy dynamics, such as that of FFS, there is no obtainable study in Uganda that has adopted the model in farming.

\section{Limitations and study forward}

This study merely covered farmer-field schools, yet several interventions aim to raise the quality of agriculture in Uganda, such as National agricultural advisory services and Emyoga. From this study, three recommendations are drawn, namely;

a) Scaling out the number of FFS at the parish level and, if possible, at every village level.

b) Local governments should be mindful of the quality of FFS, given its impetus in leading to progressive improvement in PTD.

c) Strengthen the quality of FFS as a key means to realising PTD in Hoima district and beyond.

\section{Acknowledgement}

The author acknowledges the participation of every respondent who took part in this study amidst Covid-19.

\section{References}

Adong, A. (2014). Impact of households' membership of farmer groups on the adoption of agricultural technologies in Uganda: evidence from the Uganda census of agriculture 2008/09. Agrekon, 53(2). 108-36. Doi: 10.1080/03031853.2014.915485

Besada, H., and Werner, K. (2015). An assessment of the effects of Africa's water crisis on food security and management. International journal of water resources development, 31(1). 120133. Doi: 10.1080/07900627.2014.905124

Chiaro, D., and Rossato, L. (2015). Food and translation, translation and food. The translator, 21(3). 237-243. Doi: 10.1080/13556509.2015.1110934

Etana, A., Holm, L., Rydberg, T., and Keller, T. (2020). Soil and crop responses to controlled traffic farming in reduced tillage and no-till: some experiences from field experiments and on-farm studies in Sweden. Acta agriculturae scandinavica, section B - soil \& plant science, 70(4). 333-40. Doi: 10.1080/09064710.2020.1728372

Ethical tea partnership. (2021). Creating a fairer, better, more sustainable tea industry for workers, farmers and the environment. Accessed on 22 April 2021: info@ethicalteapatnership.org

Eton, M., Mwosi, F., Ejang, M., and Poro, S.G. (2020). Financial inclusion: is it a precursor to agricultural commercialisation amongst smallholder farmers in Uganda? A comparative analysis between Lango and Buganda sub-regions. Journal of economics and international finance, 13(1). 1.12.

Feyisa, W.B. (2020). Determinants of agricultural technology adoption in Ethiopia: a meta-analysis. Cogent food \& agriculture, 6(1). Doi: 10.1080/23311932.2020.1855817

Food and agriculture organisation. (2016). Farmer filed schools in Uganda. Accessed on 22 April 2021: https://www.youtube.com/watch?v=vIoTQ8vC5Fg

Gardeazabal, A., Lunt, T., Jahn, M.M., Verhulst, N., Hellin, J., and Govaertts, B. (2021). Knowledge management for innovation in agri-food systems: a conceptual; framework. Knowledge management research \& practice. Doi: 10.1080/14778238.2021.1884010 
Gillespie, A.H., and Smith, L.A. (2008). Food decision-making framework: connecting sustainable food systems to health and wellbeing. Journal of hunger and environmental nutrition, 3(2\&3). 328-346. Doi: 10.1080/19320240802244363.

Hunter, M.C., Williamson, Z.H.D., Pearson, M., Saikawa, E., Gribble, O.M., and Kegler, M. (2020). Safe community gardening practices: focus groups with garden leaders in Atlanta, Georgia. Local environment, 25(1). 18-35. Doi: 10.1080/13549839.2019.1688268

Hwalla, N., El Labban, S., and Bahn, R.A. (2016). Nutrition security is an integral component of food security. Frontiers in life science, 9(3). 167-72. Doi: 10.1080/21553769.2016.1209133.

Ibnu, M., Offermans, A., and Glasbergen, P. (2018). Certification and farmer organisation: Indonesian smallholder perceptions of benefits. Bulletin of Indonesian economic studies, 54(3). 387-415. Doi: 10.1080/00074918.2018.1506093

Kiptot, E., and Franzel, S. (2019). Developing sustainable farmer-to-farmer extension: experiences from the volunteer farmer-trainer approach in Kenya. International journal of agricultural sustainability, 17(6). 401-12. Doi: 10.1080/14735903.2019.1679576

Lewison, E. (2019). Value chains and development brokers: engineering inclusive agricultural markets in Jumla, Nepal, South Asia. Journal of south Asian studies, 42(5). 903-19. Doi: $10.1080 / 00856401.2019 .1639244$

Madariaga, A. (2020). The three pillars of neoliberalism: Chile's economic policy trajectory in comparative perspective. Contemporary politics, 26(3). 308-29. Doi: 10.1080/13569775.2020.1735021

Makokha, S.N., Yongo, D., Mwirigi, M., and Nyongesa, D. (2019). Smallholder group dynamics and capacity building: a case study of dairy groups in Kenya. East African agricultural and forestry journal. 83(4). 281-8. Doi: 10.1080/00128325.2018.1549967

Masset, E., and Haddad, L. (2015). Does beneficiary farmer feedback improve project performance? An impact study of a participatory monitoring intervention in Mindanao, Philippines. The journal of development studies, 51(3). 287-304. Doi: 10.1080/00220388.2014.959933

Mawa, C., Babweteera, F., and Tumusiime, M.D. (2020). Conservation outcomes of collaborative forest management in a medium altitude semi deciduous forest in mid-western Uganda. Journal of sustainable forestry. Doi: 10.1080/10549811.2020.1841006

McDonald, C., Corfield, J., MacLeod, N., and Lisson, S. (2019). Enhancing the impact and sustainability of development strategies with smallholder farmers: participatory engagement, whole farm modelling and farmer-led on-farm research. International journal of agricultural sustainability, 17(6). 445-57. Doi: 10.1080/14735903.2019.1689063

Murisa, T. (2011). Local farmer groups and collective action within fast track land reform in Zimbabwe. The journal of peasant studies, 38(5). 1145-66. Doi: 10.1080/03066150.2011.634502

Nevarez, L., Tobin, K., and Waltermaurer, E. (2016). Food acquisition in Poughkeepsie, NY:, food, culture \& society. 19(1). 19-44. http://dx.doi.org/10.1080/15528014.2016.1144996.

O'Connor, T., Meredith, D., McNamara, J., O'Hora, D., and Kinsella, J. (2020). Farmer discussion groups create space for peer learning about safety and health. Journal of agromedicine. Doi: 10.1080/1059924X.2020.1720882

Ochienh, J., Knerr, B., Owuor, G., and Ouma, E. (2018). Strengthening collective action to improve marketing performance: evidence from farmer groups in central Africa. The journal of agricultural education and extension, 24(2). 169-89. Doi: 10.1080/1389224X.2018.1432493

Orina, J., Mukundi, J.B., Adimo, A.O., Rimberia, K.F., Omondi, A.M., Gebauer, J., and Kehlenbeck, K. (2021). Baobab (Adansonia digitata L.) population structure across different agroecological zones in coastal and lower eastern Kenya. Forests, trees and livelihoods, 30(1). 13-27. Doi: 10.1080/14728028.2020.1852974

Otte, P.P., Tivana, D.L., Phinney, R., Bernardo, R., and Davidson, H. (2018). The importance of gender roles and relations in rural agricultural technology development: a case study of solar fruit drying in Mozambique. Gender, technology and development, 22(1). 40-58. Doi: 10.1080/09718524.2018.1444442

Ouma, A.M., Onyango, A.C., Ombati, M.J., and Mango, N. (2020). Innovation platform for improving rice marketing decisions among smallholder farmers in Homa-Bay County, Kenya. Cogent food \& agriculture, 6(1). Doi: 10.1080/23311932.2020.1832399 
Rocha, A., Goncalves, E., and Almeida, E. (2019). Agricultural technology adoption and land use: evidence from Brazilian municipalities. Journal of land use science, 14(4-6). 320-46. Doi: 10.1080/1747423X.2019.1707312

Rusere, F., Crespo, O., Dicks, L., Mkuhlani, S., Francis, J., and Zhou, L. (2020). Enabling acceptance and use of ecological intensification options through engaging smallholder farmers in semi-arid rural Limpopo and Eastern Cape, South Africa. Agroecology and sustainable food systems, 44(6). 696-725. Doi: 10.1080/21683565.2019.1638336

Séogo, W., and Zahonogo, P. (2019). Land tenure system innovation and agricultural technology adoption in Burkina Faso: comparing empirical evidence to the worsening situation of both rural people vulnerability and vulnerable groups' access to land. African journal of science, technology, innovation and development, 11(7). 833-42. Doi: 10.1080/20421338.2019.1587257

Shita, A., Kumar, N., and Singh, S. (2020). Economic benefit of agricultural technology on Teff and maise crops in Ethiopia: the Blinder-Oaxaca decomposition. Journal of poverty, 24(3). 169-84. Doi: 10.1080/10875549.2019.1668899

Skogstad, G. (2020). Political parties and policy change in Canadian agricultural marketing institutions. Journal of comparative policy analysis: research and practice. Doi: 10.1080/13876988.2020.1749519

Templer, N., Hauser, M., Owamani, D, A., Kamusingize, H., Ogwali, L., Mulumba, R., Adugna, T.B.O., and Probst, L. (2018). Does certified organic agriculture increase agroecosystem health? Evidence from farming systems in Uganda. International journal of agricultural sustainability, 16(2). 150-66. Doi: 10.1080/14735903.2018.1440465

The FFS global platform facilitating team. (n.d). Farmer field schools global platform D-group. Accessed on 22 April 2021: http://www.fao.org/farmer-field-schools/en/

Thompson, P.B. (2015). From world hunger to food sovereignty: food ethics and human development. Journal of global ethics, 11(3). 336-50. Doi: 10.1080/17449626.2015.1100651

Tian, J., Bryksa, B.C., and Yada, R.Y. (2016). Feeding the world into the future - food and nutrition security: the role of food science and technology. Frontiers in life science, 9(3). 155-66.doi: 10.1080/21553769.2016.1174958.

USAID. (n.d). Farmer field school, curriculum: good agronomic practices for groundnut production Ghana. Accessed 22 April 2021: https//www.spring-nutrition.org

Vaghefi, N., Shamsudin, M.N., Radam, A., and Rahim, K.A. (2016). Impact of climate change on food security in Malaysia: economic and policy adjustments for rice industry. Journal of integrative environmental sciences, 13(1). 19-35. Doi: 10.1080/1943815X.2015.1112292

Van Den Berg, H. and Knols, B.G.J. (2006). The farmer field school: a method for enhancing of rural communities in malaria control? BMC Malaria journal, 5(3).

Vercillo, S., Kuuire, V.Z., Armah, F.A., and Luginaah, I. (2015). Does the new alliance for food security and nutrition impose biotechnology on smallholder farmers in Africa? Global bioethics, 26(1). 1.13. Doi: 10.1080/11287462.2014.1002294.

Zhang, J., Wu, J., Simpson, J., and Arthur, L.C. (2019). Membership of Chinese farmer specialised cooperatives and direct subsidies for farmer households; a multi-province data study. The Chinese economy, 52(5). 400-21. Doi: 10.1080/10971475.2019.1617928

Zheng, C., and Huang, H. (2018). Analysis of technology diffusion in agricultural industry cluster based on system dynamics and simulation model. Journal of discrete mathematical sciences and cryptography, 21(6). 1211-4. Doi: 10.1080/09720529.2018.1525129 